\title{
KEAMANAN FTP SERVER BERBASISKAN IDS DAN IPS MENGGUNAKAN SISTEM OPERASI LINUXUBUNTU
}

\author{
Shah Khadafi ${ }^{1)}$, Yuni Dian Pratiwi ${ }^{2)}$, Enggar Alfianto ${ }^{3)}$

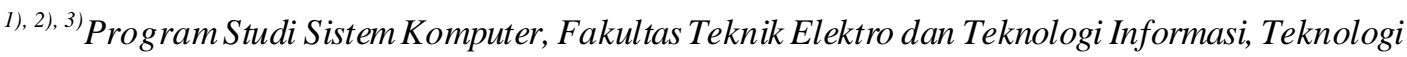 \\ Adhi Tama Surabaya(ITATS) \\ Jl. Arief Rahman Hakimno 100, Surabaya, \\ E-mail:khadafi@itats.ac.id ${ }^{1)}$,yunidianpratiwi@gmail.com ${ }^{2)}$,enggar@itats.ac.id ${ }^{3)}$ \\ Corresponding author phone: +6281520451155
}

\begin{abstract}
Abstrak
Vulnerability komputer server pada jaringan komputer dapat dimanfaatkan hacker atau attacker melakukan tindakan yang tidak sah yang bertujuan mengacaukan sistem sebuah komputer. Pada tahun 2020 tercatat bahwa serangan yang dilakukan oleh hacker terjadi setiap 39 detiknya, tercatat juga komputer yang digunakan sebagai penelitian telah diserang sebanyak 2.244 kali per ha rinya. Sniffing a dalah salah adalah ancaman keamanan utama dalam komputasi bentuk komunikasi client-server. Pada penelitian ini membangun sebuah sistem kea manan data pada komputer FTP server dengan menerapkan Instrusion Detection System (IDS) dan Instrusion Prevention System (IPS). Hasilnya Aplikasi Portsentry sangat efektif dan sangat baik dalam mendeteksi adanya aktivitas scanning port, dan juga sangat baik dalam memblokir sera ngan dari attacker, hal ini dika renakan Portstentry memiliki mekanisme untuk mencatat IP address yang dimilki oleh attacker melalui file system portsentry.ignore.static. Aplikasi Snort sangat efektif ketika mendeteksi semua jenis serangan baik itu serangan ping of death, scanning port maupun sniffing, hal ini dika renakan Snort memiliki mekanisme mode detection untuk memberikan informasi peringatan a tau alert kepada admin jaringan bila terdapat intruder melalui rules command di dalam file system Snort. Sehingga Portsentry dan Snort cukup efektif dalam menerapkan sistem IDS dan IPS pada FTP server.
\end{abstract}

Kata kunci : Ftp, Ids, Ips, Portsentry, Snort.

\section{Abstract}

The vulnerability of a server computer on a computer network can be used by hackersor attackers to carry out illegal actions aimed at disrupting a computer system. In 2020 it was noted that attacks carried out by hackers occurred every 39 seconds, It was also noted that the computers usedfor research were attacked 2,244 times per day. Sniffing is a major security threat in computing this form of client-server communication. In this study, building a data security system on an FTP servercomputer by implementing the Instrusion Detection System (IDS) and the Instrusion Prevention System (IPS). The result is that the Portsentry application is very effective and very good at detecting port scanning activity, and also very good at blocking attacks from attackers. this is because Portstentry has a mechanism to log the IP address that is owned bythe attacker through the portsentry.ignore.staticfile system. The Snort application is very effective when it detects all types of attacks, be it ping of death attacks, port scanning or sniffing, this is because Snort has a detection mode mechanism to provide warning information or alerts to the network admin if there is an intruder through the rules command in the Snort file system. So that Portsentry and Snort are quite effective in implementing IDS and IPS systems on FTP servers.

Keywords : ftp, ids, ips, portsentry, Snort.

\section{PENDAHULUAN}

Keamanan jaringan komputer mencakup berbagai resource apa saja yang terdapat di dalam jaringan komputer tersebut, baik itu jaringan yang bersifat network public (jaringan umum) maupun jaringan yang bersifat network private (jaringan pribadi). Kepentingan penggunaan jaringan komputer sangatlah tinggi, dimana kepentingannya yang harus terus menerus dapat digunakan dalam pekerjaan sehari-hari, diantaranya melakukan transaksi pembelian atau penjualan, kegiatan komunikasi antar perusahaan, komunikasi lembaga pemerintahan, maupun komunikasi antar individu yang satu dengan yang lainnya. Penggunaan jaringan komputer disini dapat bersifat pribadi, contohnya seperti aktivitas kerja yang melibatkan koneksi jaringan komputer pada sebuah perusahaan. Sistem keamanan jaringan komputer pada perusahaan terdapat kebijakan yang dapat diterapkan untuk mencegah terjadinya uanthorized access dari user yang tidak diizinkan, pencegahan dari percobaan modifikasi sebuah informasi atau data, pencegahan 
terhadap aktivitas Denial of Service (penolakan jaringan komputer) dan digunakan untuk memantau resource network computer yang dapat diakses user. Sistem keamanan jaringan komputer juga melibatkan aktivitas authorization access ke data yang tersambung dalam jaringan, dimana sistem keamanan yang seperti ini dikendalikan oleh seorang administrator jaringan. Secara implementasinya pengguna dapat mengakses baik menggunakan username atau diberikan ID (identitas khusus) dan juga pemberian kata sandi ataupun informasi otentikasi lainnya yang memungkinkan pengguna dapat mengakses informasi dan program dalam kewenangan pengguna tersebut.

Vulnerability (kerentanan) terhadap jaringan komputer dapat dimanfaatkan oleh seseorang hacker atau attacker untuk melakukan tindakan yang tidak sah ataupun dari malware yang bertujuan untuk mengganggu sistem ataupun mengacaukan sistem kerja sebuah komputer. Dari sebuah laman web sebuah studi yang dilakukan di University of Maryland adalah salah satu yang kegiatan pertama yang menghitung tingkat serangan oleh hacker yang hampir konstan dari komputer dengan akses internet, dimana yang membahas mengenai serangan malware dan serangan hacker pada akhir-akhir ini semakin meningkat, pada tahun 2020 tercatat bahwa serangan yang dilakukan oleh hacker setiap 39 detik. Selain itu tercatat bahwa komputer yang digunakan sebagai penelitian telah diserang sebanyak 2.244 kali per harinya. Untuk mencapai target komputer sasaran, hacker kebanyakan mencapainya dengan cara melalui backdoor (pintu belakang) atau pintu masuk yang tidak terdeteksi yang tidak diketahui oleh pemilik komputer.

Dari berbagai serangan komputasi, serangan distributed denial of service (DDoS), man-inthe-middle attack (MITM) dan pencurian data memiliki dampak besar pada aplikasi yang sedang berkembang. Serangan sniffing, salah satu alasan paling menonjol untuk serangan DDoS, adalah ancaman keamanan utama dalam komputasi bentuk client-server [1]. Salah satu bentuk komputasi dan komunikasi client-server adalah aktivitas file transfer, yang menyediakan protokol tertentu untuk melakukan pertukaran file yang disebut dengan dengan file transfer protocol (FTP). FTP server menyediakan laynan file transfer antar mesin komputer dalam sebuah network. FTP protokol level aplikasi dalam Open System Interconnection (OSI) yang digunakan sebagai standar proses file transfer. Inisialisasi transfer FTP pada port nomor 21 menggunakan port TCP (transmission control protocol) sebagai komunikasi data komputer client dan server [2].

Sistem keamanan pada komputer yang menyediakan layanan FTP sangat penting dalam melindungi komputer baik client maupun server yang menyediakan file dari serangan sniffing. Penelitian ini merancang sistem keamanan pada komputer FTP server yang dapat mendeteksi adanya penyusup atau attacker. Metode yang digunakan pada penelitian ini menggunakan intrusion detection system (IDS) dan intrusion prevention system (IPS), dimana metode ini mampu mendeteksi adanya unauthorized access (akses yang tidak sah) dari sebuah sistem dengan cara melakukan pengamatan traffic jaringan secara real-time. Pentingnya penggunaan IDS dan IPS pada sebuah komputer dengan layanan FTP dapat menggantikan peran firewall dalam menahan serangan dari penyusup. Sebagai solusi dalam mendeteksi dan pencegahan adanya serangan oleh attacker, maka pada penelitian ini menggunakan program aplikasi untuk keamanan FTP yaitu program portsentry dan Snort dimana keduanya merupakan software application program yang bersifat open source yang dapat berjalan di sistem operasi linux.

\section{DASAR TEORI}

\subsection{Intrusion Detection System (IDS)}

IDS merupakan teknik khusus yang dapat digunakan seorang admin jaringan komputer yang bertanggung jawab untuk mengamankan akses jaringan komputer dari penyusup (intruder) yang sedang melakukan intrusion (gangguan)[3]. Metode IDS ini digunakan untuk dapat mengetahui atau mendeteksi adanya aktivitas jaringan oleh pengguna tertentu atau attacker yang aktivitasnya dianggap mencurigakan (sniffing). Dari analisa sebuah penelitian [4], bahwa cara kerja IDS ini dapat dianalisa tahapannya yang terdapat 4 tahapan yang dapat dijelaskan sebagai berikut : 
1. Pertama Knowledge-based digunakan untuk mengenali adanya penyusupan dengan cara menyadap paket data kemudian membandingkannya dengan database rule IDS yang berisi signature-signature paket serangan.

2. Kedua Behavior based (anomaly) digunakan untuk mendeteksi adanya penyusupan dengan mengamati adanya kejanggalan pada sistem, atau adanya penyimpangan-penyimpangan dari kondisi normal.

3. Ketiga Passive IDS berfungsi sebagai pendeteksi atau sebagai komponen yang menghasilkan respons, yang menghasilkan alarm jika terdeteksi adanya gangguan.

4. Keempat Reactive IDS berfungsi sebagai pendeteksi dan pemberi peringatan sekaligus mengambil tindakan pemblokiran untuk merespon terhadap serangan yang ada.

Sedangkan jika dilihat pada kemampuan IDS dibagi menjadi 5 jenis antara lain yaitu network intrusion detection system (NIPS), host-based intrusion detection system (HIDS), protocol-based intrusion detection system (HIDS), application protocol-based intrusion detection system (HIDS), hybrid-based intrusion detection system (HIDS) [5].

Network intrusion detection system (NIDS) terdiri beberapa peranti jaringan dengan peranti yang dilengkapi dengan network interface card (NIC) yang dapat ditempatkan pada sebuah komputer yang terkoneksi dengan jaringan. Sistem IDS dapat melakukan monitoring semua lalu lintas jaringan data, yang dapat diilustrasikan pada gambar 1 .

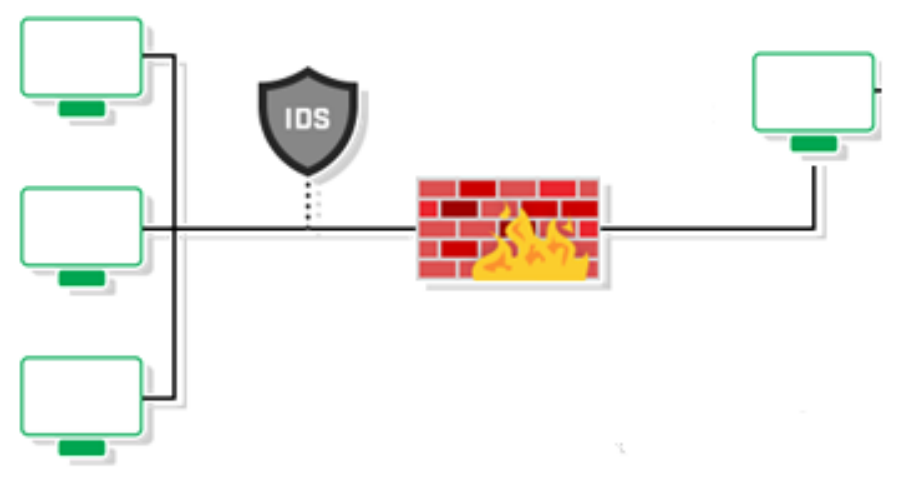

Gambar 1. Ilustrasi Sistem IDS pada Jaringan Komputer

\subsection{Snort}

Snort merupakan suatu tools paket instalasi sistem linux, yang fungsi utamanya dapat digunakan untuk mendeteksi adanya penyusup (threats) [3]. Selain itu Snort mampu menganalisis paket yang melintasi jaringan secara real time dan file logging ke dalam databasee. Snort merupakan salah satu contoh jenis IDS yang termasuk kategori network-based intrusion detection system (NIDS), yaitu sebuah program sistem yang dapat mendeteksi suatu (intrusion) penyusupan di dalam sistem jaringan komputer. Snort juga dapat bekerja sebagai mode packet sniffer yang memungkinkan sistem dapat membaca traffic jaringan komputer, dan Snort juga dapat bekerja dalam mode packet-logger yang memugkinkan sistem mencatat traffic jaringan dan memberi peringatan yang terjadi.

Snort dapat digunakan sebagai tools untuk pendeteksi dan juga untuk mencegah apabila terindikasi sebuah paket data yang terdapat pada traffic jaringan teridentifikasi sebagai threats atau terdeteksi sebagai ancaman. Di dalam Snort juga memilki rules (aturan layaknya firewall) sebagai pendeteksi threats dengan cara memantau setiap traffic data yang lewat di dalam jaringan. Implementasi aplikasi Snort ini menggunakan rules set (set aturan) yang mempunyai penulisan aturan khusus sehingga sistem linux dapat menjalankan aturan-aturan untuk mengenali pola serangan yang dilakukan oleh pelaku attacker, jika pola perilaku abnormal telah terdeteksi, maka Snort akan memberikan peringatan. 


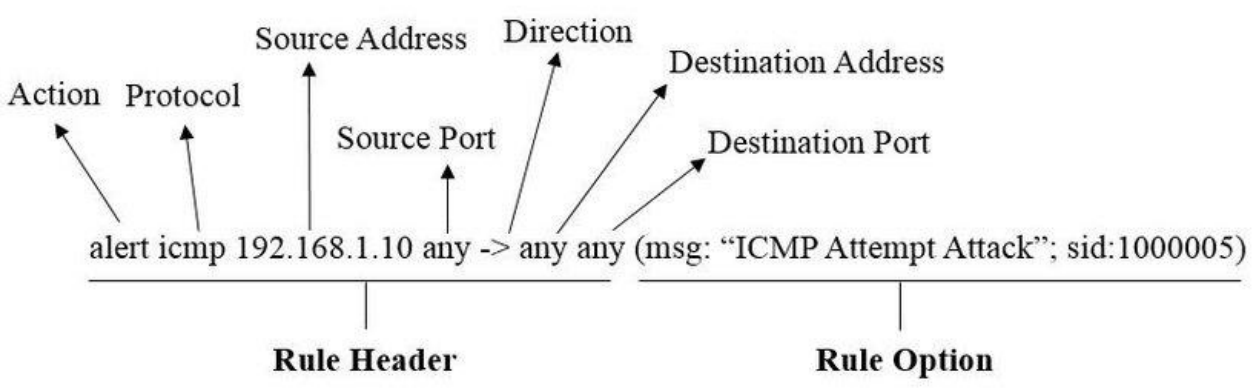

Gambar 2. Format penulisan rules Snort pada sistem linux[6]

Penulisan aturan atau rules pada Snort terdapat dua bagian yang harus diperhatikan yaitu bagian header and option rules. Aturan-aturan pada rule header berfungsi sebagai tindakan apa yang harus dilakukan, misalnya memantau protokol tertentu, alamat IP asal dan alamat IP tujuan, dan nomor port asal dan tujuan. Pada action field yang terdapat pada header rule yang memiliki tiga property yaitu, alert, $\log$, dan pass. Protocol field bertindak sebagai kriteria untuk mendeteksi data traffic yang masuk dalam jaringan, protokol yang dideteksi bisa mencakup port IP, TCP, UDP, maupun port ICMP. Aturan pada Snort juga terdapat IP address sumber dan IP address tujuan. Direction field ditulsikan dengan "->", "<-" dan "<>" yang menjelaskan arah data traffic jaringan antara komputer sumber dan komputer tujuan. Port field menjelaskan mengenai kriteria dalam aturan Snort untuk menentukan protocol port mana yang digunakan. Lebih lanjut, jika ingin menentukan setiap port, field dari port tersebut didefinisikan dengan penulisan "any" [6].

Sedangkan aturan-aturan pada rule options berfungsi untuk menampilkan pesan-pesan yang akan ditampilkan dan juga untuk menentukan paket seperti apa yang nantinya harus diamati. Fitur options rule memiliki dua bagian utama yaitu, keyword dan argument yang dituliskan di dalam tanda kurung "()" dan dipisahkan dengan titik koma ";”. Keyword options dipisahkan dari argumen dengan titik dua “:”. Sedangkan untuk rules Snort sendiri dapat memiliki lebih dari satu opsi dalam rule options. Contoh keyword options adalah $m s g, t t l$, tos, dan icode.

\subsection{Firewall}

Firewall adalah program sistem yang berbentuk tools paket instalasi sistem linux yang berfungsi untuk memproteksi atau pencegahan komputer dari akses user yang tidak diinginkan yang dapat masuk melalu akses jaringan komputer. Sistem proteksi yang dimiliki firewall dapat berupa penolakan (reject), pembatasan akses (access limited), dan penyaringan akses (filtering) yang dianggap aman. Firewall selalu ada pada setiap jenis sistem operasi. Firewall berperan sebagai filter antara komputer internal dan eksternal. Selain itu, firewall juga berfungsi mengatur dan mengontrol lalu lintas data yang diijinkan untuk mengakses jaringan private [7].

Salah satu firewall dalam sistem operasi linux adalah iptables. Dengan menerapkan iptables pada sistem linux maka dapat dijadikan sebagai gerbang keamanan (gateway) antara jaringan komputer internal dan jaringan komputer eksternal. Cara kerja firewall berfungsi layaknay sebagai dinding atau tembok yang membatasi komputer dari jaringan internet. Digambarkan sebagai "tembok api" inilah keaman jaringan bisa diatur baik data, informasi, dan kegiatan apa yang boleh melewati atau tidak boleh dari jaringan internet ke komputer dan begitupun pula sebaliknya seperti yang diilustrasikan pada gambar 3. Firewall dan iptables bertindak sebagai pertahanan dalam mencegah jenis hacking ke dalam jaringan, karena setiap hacker yang mencoba menembus ke dalam jaringan komputer akan mencari port yang terbuka dan dapat diaksesnya.

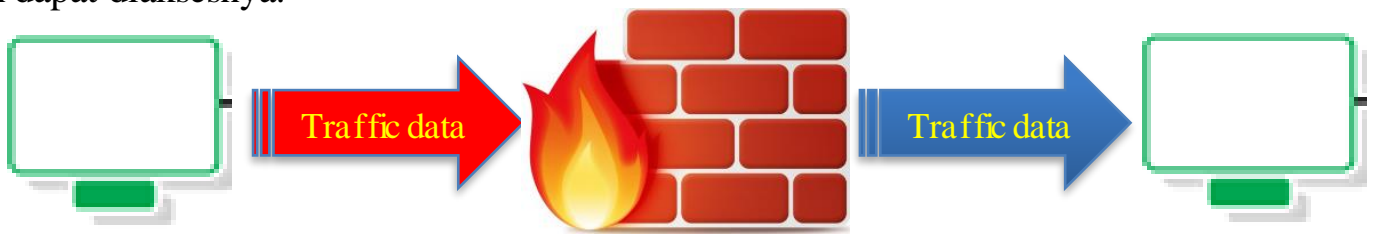

Gambar 3. Cara Kerja Firewall 


\subsection{Portsentry}

Aplikasi portsentry merupakan sebuah sistem yang diimplementasikan untuk mendeteksi adanya aktvitas serangan oleh attacker pada suatu komputer host (dalam hal ini komputer server) dengan cara melakukan scanning port. Dengan melakukan serangan ini, cara scaning port yang dilakukan oleh attacker terhadap komputer server dengan memeriksa port yang terbuka dari komputer server. Selain mampu mendeteksi serangan scanning port, portsentry juga dapat melakukan pencegahan atau memblokir akses terhadap port komputer host atau server dengan cara menutup semua port tersebut yang ada pada komputer server, sehingga attacker tidak dapat menemukan port yang dijadikan target sasaran scanning dalam keadaan terbuka. Dengan menutup port melalui teknik pemblokiran menggunakan portsentry, maka IP address yang digunakan oleh attacker diblokir, sehingga akibatnya IP address milik attacker tidak dapat terhubung kembali pada komputer server. Kelebihan lain dari aplikasi portsentry adalah dapat mencatat dan mengingat alamat IP dari penyusup [8]. Portsentry merupakan aplikasi yang digunakan untuk menghindari berbagai aktifitas scanning. Portsentry dapat mengingat IP address dari penyerang. Proses yang dilakukan attacker yaitu proses scanning terhadap server menjadikan server tersebut seolah-olah terlihat down bahkan semua port terlihat tertutup.

Tools untuk menerapkan IDS pada jaringan komputer yang menggunakan sistem Linux yaitu Portsentry didesain secara khusus untuk mendeteksi dan merespon adanya aktivitas kegiatan scanning port oleh attacker pada sebuah komputer server secara real time. Ketika sistem mendeteksi adanya intruder, maka aplikasi portsentry secara otomatis akan menjalankan firewall melalui rules yang terdapat pada iptables, dan selanjutnya sistem juga akan menjalankan TCP Wrapper yang digunakan untuk memblokir akses attacker ke komputer server dengan cara melakukan rejecting koneksi dan filtering IP address milik penyerang, sehingga serangan scanning port dapat digagalkan. Selanjutnya portsentry akan mencatat aktivitas serangan scanning port melalui $\log$ yang hasilnya dicatat dan disimpan ke dalam file syslog. Dengan syslog-notify data log yang tersimpan di syslog dapat ditampilkan di layar monitor [9].

\section{METODOLOGI PENELITIAN}

Pada penelitian kali ini akan dirancang sebuah sistem keamanan data pada komputer FTP server dengan menerapkan IDS dan IPS. Terdapat 3 bagian rancangan untuk penelitian ini yaitu, yang pertama rancangan topologi jaringan, yang kedua rancangan sistem keamanan Snort dan portsentry, dan yang terakhir perencanaan pengujian sistem kemananan FTP server menggunakan IDS dan IPS dengan portsentry dan Snort dengan cara melakukan beberapa jenis serangan yang dilakukan oleh attacker.

\subsection{Topologi jaringan}

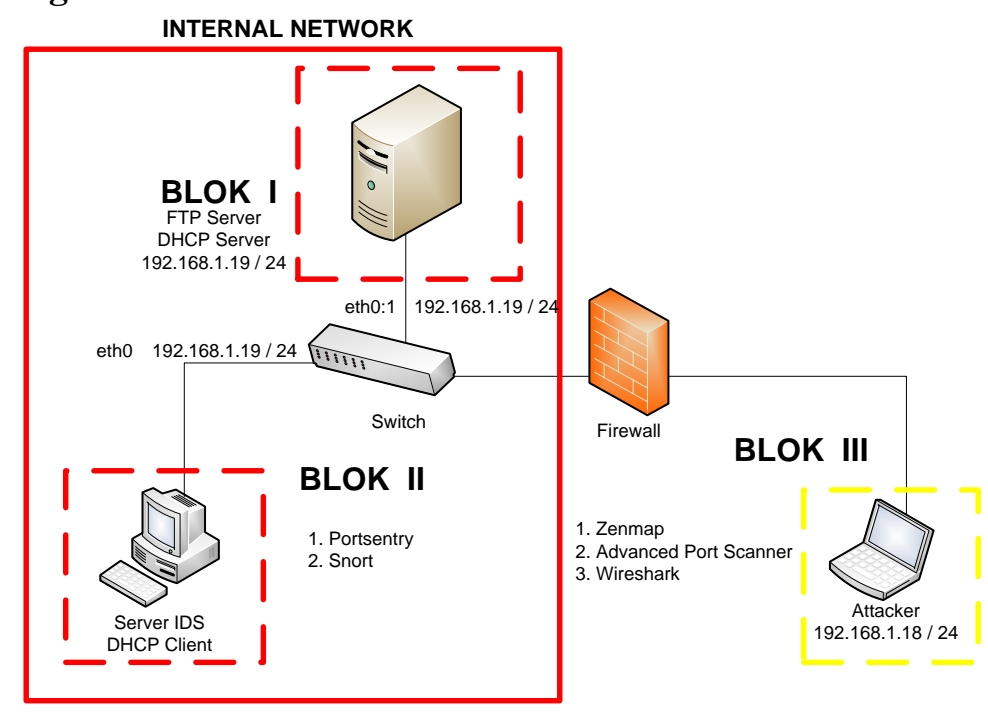

Gambar 4. Topologi jaringan yang dikembangkan

Pada gambar topologi jaringan sistem kemananan komputer FTP server menggunakan IDS dan IPS, bahwa topologi yang digunakan terdiri dari 3 blok sistem. Blok 1 terdiri dari 1 buah 
komputer server dengan sistem operasi Linux yang menjalankan layanan FTP. Blok 2 terdiri dari 1 buah komputer sebagai sistem pengaman IDS dengan sistem operasi linux ubuntu 16.04 yang menjalankan software application program Snort dan portsentry. Blok 3 terdiri dari 1 buah komputer client yang bertindah sebagai komputer attacker dengan sistem operasi Windows 7 yang di dalamnya terinstall aplikasi untuk hacking yaitu zenmap, port scanner, advanc port scanner dan wireshark.

\subsection{Rancangan sistem keamanan IDS dan IPS}

Sistem keamanan pada komputer FTP server menggunakan IDS dan IPS menggunakan Snort dan portsentry. Sistem IDS menggunakan Snort bekerja dengan melakukan monitoring paket yang melintas dalam jaringan. Kemudian Snort akan memeriksa setiap paket yang masuk melalui traffic jaringan dengan database rule Snort. Traffic tersebut kemudian dibandingkan dengan rules Snort, jika pada traffic jaringan terdeteksi adanya ancaman, maka Snort akan menampilkan pesan peringatan (alert) real-time pada admin melalui tulisan pesan pada layar komputer. Rancangan flowchart sistem IDS ditunjukkan pada gambar 5(a). Sistem portsentry bekerja jika ditemukan adanya sniffer (penyusup) yang kedapatan melakukan scanning port, kemudian Portsentry akan melakukan filtering terhadap port TCP (transfer control protocol) maupun UDP (user datagram protocol). Selanjutnya sistem akan mencatat IP address yang dimiliki oleh attacker tersebut kedalam file log system, dan kemudian memblokir serangan yang terjadi. Namun, jika sistem tidak menemukan aktivitas scanning port maka traffic data yang masuk pada jaringan akan diproses dan selanjutnya diputuskan bahwa traffic yang masuk tersebut diloloskan masuk ke dalam jaringan. Rancangan flowchart porsentry ditunjukkan pada gambar 5.

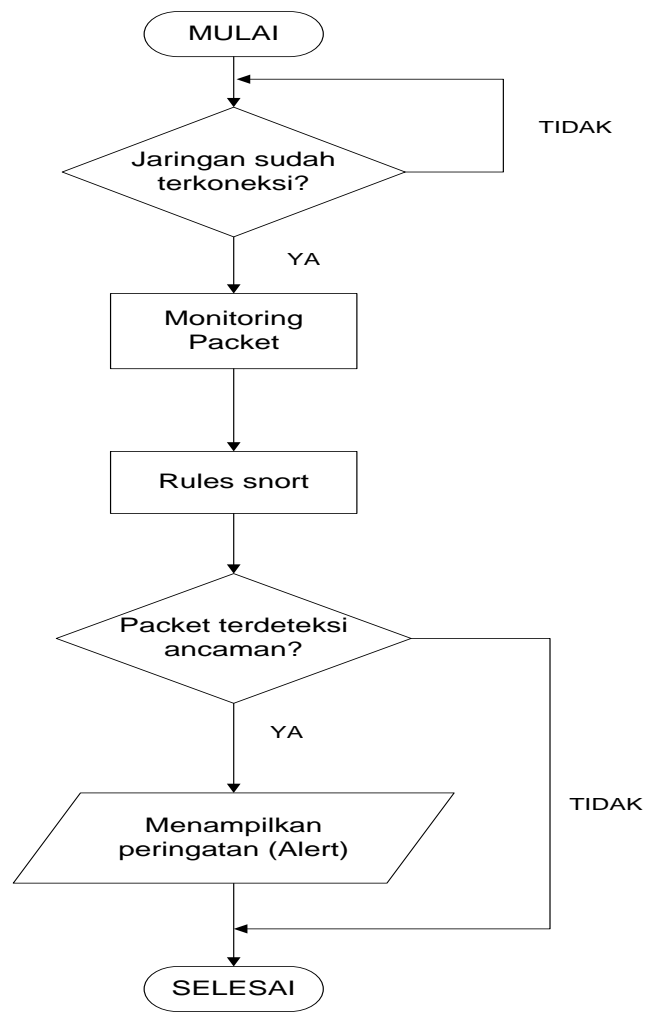

(a)

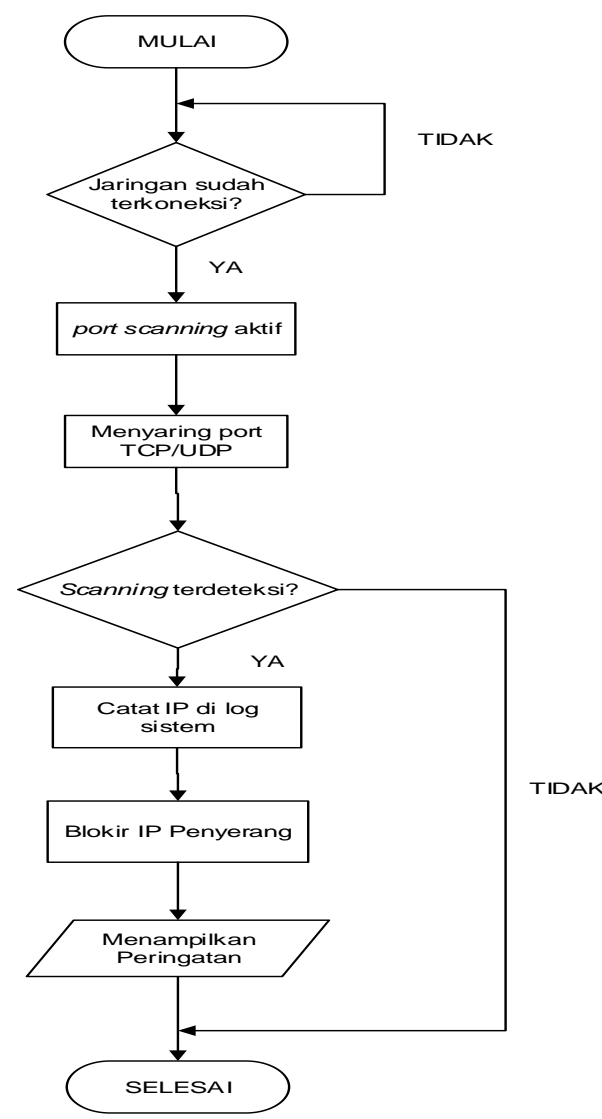

(b)

Gambar 5. (a) Flowchart System IDS, (b) Flowchart System IPS

Pada gambar 5.(a) menggambarkan mengenai cara kerja portsentry, pertama-tama yang dilakukan ialah memastikan adanya jaringan komputer yang terkoneksi dengan baik, saat jaringan komputer saling terkoneksi, proses selanjutnya ialah mengaktifkan port scanning. Jika sistem 
mengetahui ada penyerang yang sedang melakukan aktivitas scanning, maka sistem program portsentry melakukan penyaringan terlebih dahulu pada port TCP dan UDP, apabila ditemukan proses scanning maka program portsentry akan mencatat IP penyerang kedalam log sistem dan kemudian memblokir akses dari IP address penyerang. Namun, jika tidak ditemukan aktivitas scanning oleh program portsentry maka proses tersebut dapat diteruskan.

Progam Snort juga memilki fitur untuk mendeteksi adanya penyusup yang masuk di dalam jaringan. Pada gambar 5.(b) menggambarkan cara kerja portsentry untuk mendeteksi adanya penyusup. Konsep kerjanya ialah melakukan program portsentry monitoring traffic paket data yang lewat pada jaringan. Untuk menyusun sistem untuk monitoring traffic paket tersebut dibuat melalui aturan-aturan yang telah di setting atau ditentukan untuk mendeteksi adanya serangan. Jika traffic paket yang lewat tersebut dianggap mencurigakan dan sesuai rules yang telah dibuat, maka Snort akan menampilkan peringatan (alert) secara langsung kepada user apabila memang ditemukan adanya penyusup.

\subsection{Konfigurasi portsentry dan Snort}

Rancangan sistem keamanan IDS dan IPS yang dirancangan dalam penelitian ini mengkombinasikan aplikasi Snort dan portsentry. Aplikasi portsentry ini dapat menentukan jenisjenis paket yang akan dilakukan monitoring yang masuk ke traffic jaringan komputer baik melalui port TCP maupun UDP. Portsentry akan melakukan filtering terhadap port komputer bila terjadi penyerangan port scanning melalui file konfigurasi portsentry melalui command BLOCK_TCP dan BLOCK_UDP. Konfigurasi mode untuk melakukan filtering ketika Portsentry mendeteksi adanya aktivitas scanning port TCP/UDP, maka bisa dilakukan konfigurasi mode deteksi port pada file letc/default/portsentry dengan mengubahnya menjadi $T C P \_M O D E=$ "atcp" dan $U D P \_M O D E=$ "audp". Rancangan sistem keamanan Portsentry ini mirip dengan rule pada firewall dimana Portsenstry juga terdapat rule untuk mengamankan sebuah komputer dengan sistem operasi Linux Ubuntu 16.04. File konfigurasi portsentry dapat ditemukan pada file portsentry.conf yang dapat ditemukan pada directory /etc/portsentry/. Berikut ini adalah adalah aturan-aturan portsentry untuk rancangan sistem keamanan yaitu :

- KILL_ROUTE=”/sbin/iptables -I INPUT - s $\$ T A R G E T-j$ DROP

rule pada portsentry ini digunakan untuk menolak percobaan koneksi dari attacker melalui penyerangan yang dilakukannya melalui scanning port.

- KILL_HOSTS_DENY="ALL: \$TARGET\$:DENY"

rule pada portsentry ini digunakan untuk melakukan filtering akses IP address host penyerang ketika melakukan scanning port melalui jaringan komputer.

Tampilan interface pada sistem linux untuk rules pada portesntry nampak pada gambar 6 di bawah ini.

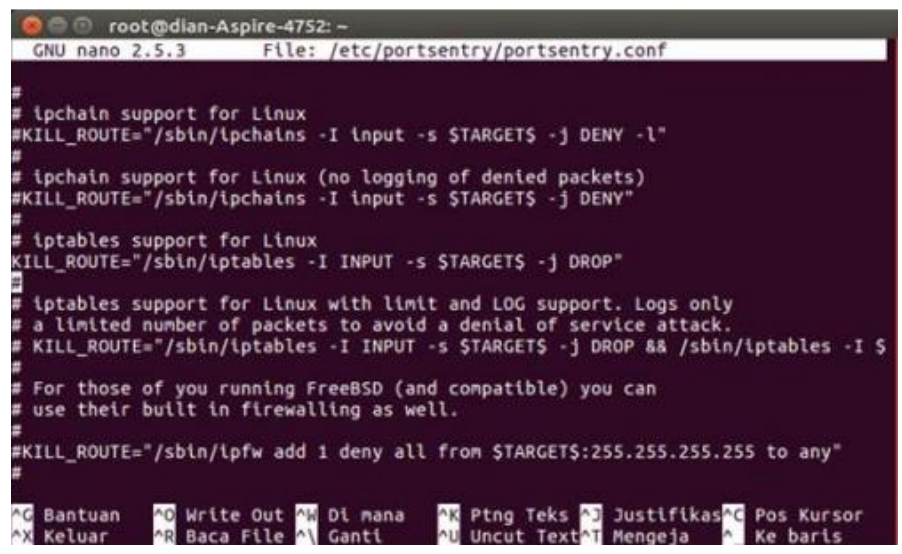

Gambar 6. Konfigurasi reject connectios dengan iptables

Aplikasi Snort dapat melakukan monitoring paket traffic pada jaringan komputer. Konsep dari Snort ini memiliki rules yang dapat digunakan untuk mendeteksi adanya serangan dari attacker. Konfigurasi file system Snort terletak pada file local.rules yang berada pada direktori /rules. Rules command yang dituliskan pada Snort untuk rancangan keamanan sistem yaitu : 
- alert icmp any any -> \$HOME_NET any (msg: "Ping of Death Detection"; dsize:>10;sid:449;rev:4;)

- alert tcp any any -> \$HOME_NET 21 (msg: "Login FTP

Detection";sid:10000002;rev:1;)

- alert tcp 192.168.1.1921 -> any any (msg: "FTP Failed Login”; content: "Login and Password Incorrect"; sid:10000003;rev:1;)

- alert tcp any any -> 192.168.1.1922 (msg: "Portscan FTP

Detection";sid:10000004;rev:1;)

Tampilan konfigurasi Snort pada sistem linux nampak pada gambar 7 di bawah ini.

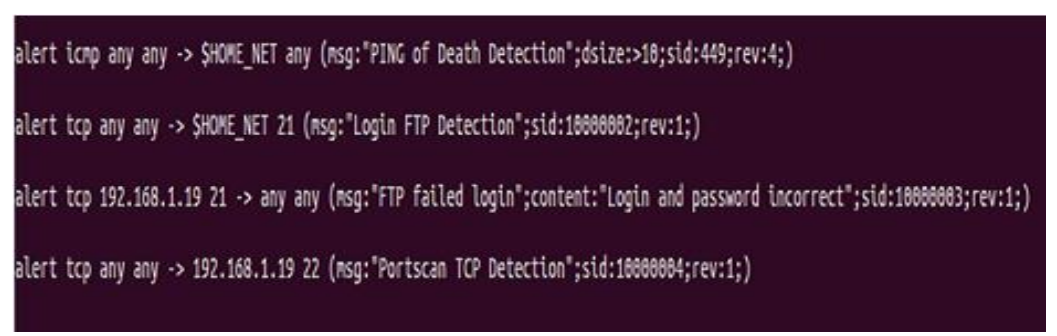

Gambar 7. Konfigurasi Snort

File konfigurasi yang lain dari Snort pada Ubuntu 16.04 terletak pada file konfigurasi Snort.conf yang terletak pada directory /etc/Snort. Peritah yang dituliskan pada rule Snort untuk rancangan keamanan sistem yaitu:

- ipvar HOME_NET 192.168.1.0/24

Tulisan rule pada konfiurasi Snort ini untuk menentukan network address yang akan dilakukan monitoring yaitu network 192.168.1.0

- include \$RULE_PATH/local.rules

Tulisan rule pada konfiurasi Snort ini untuk merancang aturan keamanan sistem melalui file local.rules

\section{PENGUJIAN DAN PEMBAHASAN}

\subsection{Pengujian pada komputer FTP server}

Pada tahap pengujian dilakukan dengan cara melakukan serangan ke komputer FTP server dengan IP address 192.168.1.19 yang sebelumnya sudah terinstall sistem keamanan IDS dan IPS. Jenis-jenis serangan yang digunakan untuk pengujian pada komputer FTP server pada penelitian ini antara lain :

- Pengujian Ping of Death dengan portsentry : teknik penyerangan ini mengirim paket secara terus-menerus agar kinerja sistem pada target mengalami hang atau berhenti bekerja seperti penyerangan jenis Denial of Service [10]. Serangan jenis ini biasanya dimanfaatkan oleh seorang attacker untuk menyerang FTP server dengan mengirim paket icmp dalam jumlah besar dan sebanyak mungkin supaya membuat komputer FTP server menjadi lebih lambat dalam merespon request dari client. Pengujian ping of death dilakukan seperti biasa dengan melalui command prompt pada komputer attacker.

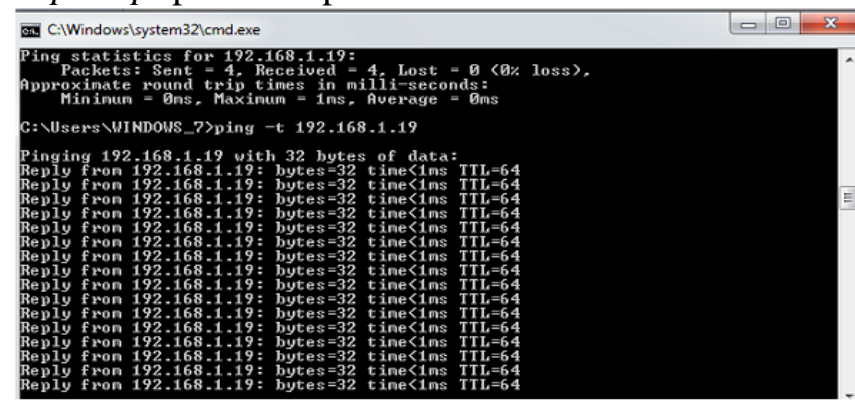

Gambar 8. Serangan Ping of Death Pada FTP Server 
Pada gambar 6 diatas, menunjukkan serangan ping of death yang diimplementasikan dengan menggunakan command line interpreter pada komputer dengan sistem windows yang menggunakan program aplikasi command prompt. Serangan dilakukan dengan perintah ping - $t$ 192.168.1.19, dimana perintah ping - $t$ merupakan mengirimakan data packet secara terus menerus menuju ke komputer korban yaitu dengan IP address 192.168.1.19.

- Port Scanning : port scanning adalah serangkaian pesan yang dikirim oleh attacker yang mencoba masuk ke komputer server untuk mempelajari layanan jaringan komputer mana yang terkait dengan port target sasaran penyerangan yang bertujuan untuk menyelidiki kelemahan sistem [11]. Port Scanning merupakan sebuah teknik hacking dimana seorang attacker dapat membobol komputer server melalui port yang terbuka untuk dieksekusi. Program aplikasi advance port scanner dan zenmap merupakan tools yang sering digunakan untuk melakukan aktivitas port scanning.

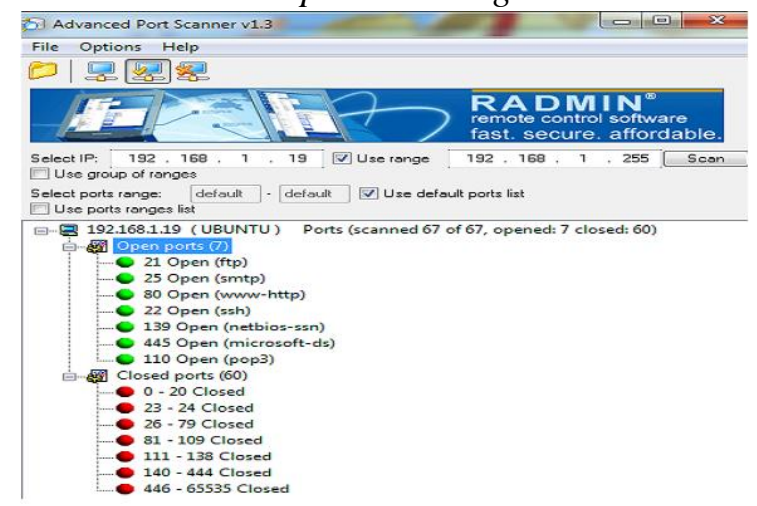

Gambar 9. Serangan Port Scanning Menggunakan Advance Port Scanner

Pada gambar 9 diatas, menunjukkan serangan port scanning yang diimplementasikan dengan menggunakan program aplikasi advance port scanner pada komputer dengan sistem windows. Pada gambar 9 tersebut serangan ditujukan pada komputer korban dengan IP address 192.168.1.19 yang menunjukkan hasil dari serangan port scanning menunjukkan bahwa terdapat 7 port yang terbuka dan 60 port tertutup.

- Sniffing: Sniffing adalah serangan terhadap kerahasiaan informasi ataupun data [12]. Tujuan utama dari sniffer adalah untuk mencuri password dan file (seringnya pada FTP server). Pengujian serangan sniffing dilakukan menggunakan aplikasi Wireshark. Tujuan attacker melakukan sniffing yang diimplementasikan menggunakan program aplikasi Wireshark adalah untuk mengetahui paket-paket jaringan yang sedang melintas pada traffic jaringan lokal, dan kemudian aplikasi Wireshark akan membaca paket-paket yang melintas beserta aktifitas dari paket tersebut.

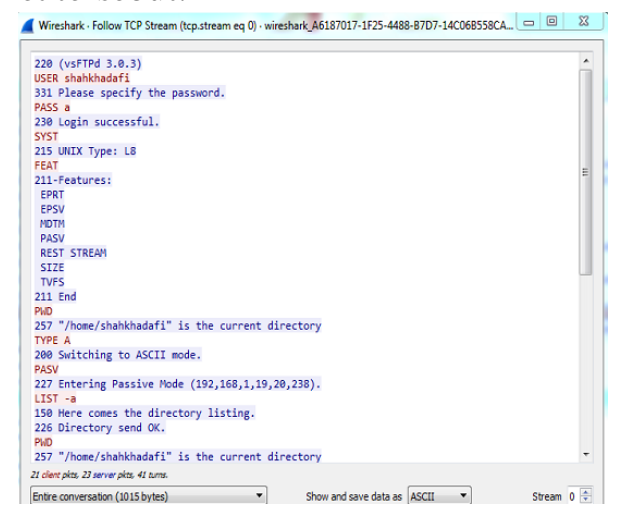

Gambar 10. Serangan Sniffing Menggunakan Wireshark 
Pada gambar 10, menunjukkan serangan Sniffing yang diimplementasikan dengan menggunakan program aplikasi Wireshark pada komputer dengan sistem windows. Pada gambar 10 tersebut serangan ditujukan pada komputer korban dengan IP address 192.168.1.19, dimana setelah username dan password berhasil didapatkan penyusup akan segera melakukan login pada FTP dengan username shahkhadafi dan password (yang telah diketahui), maka penyusup sudah dapat mengakses dan mengambil data-data penting tanpa diketahui oleh siapapun.

\subsection{Pembahasan hasil pengujian}

Pada tahap hasil pengujian ini dilakukan dengan mengimplementasikan sistem melalui konfigurasi dan rules yang sudah dirancang sebelumnya. Hasil pengujian serangan dilakukan pada Porsentry dan Snort.

Pengujian Ping of Death dilakukan sebanyak dua kali pengujian dengan menggunakan menggunakan program aplikasi command prompt.

- Pengujian ping of death pada Portsentry : Pengujian serangan ping of death dilakukan untuk menguji apakah Portsentry dapat mendeteksi jenis serangan tersebut atau tidak. Setelah dilakukan pengujian serangan ping of death, hasilnya Portsentry tidak dapat mendeteksi adanya serangan tersebut seperti yang nampak pada gambar 11.

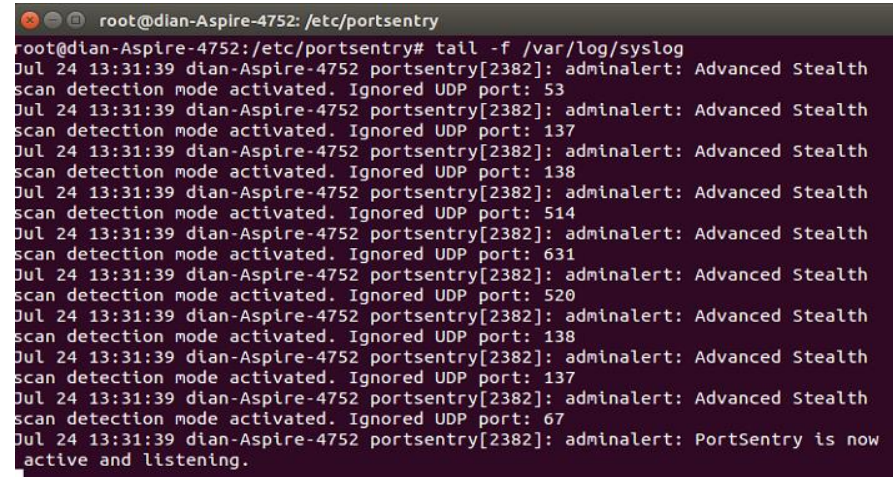

Gambar 11. Hasil Tidak Terdeteksinya Serangan Ping of Death Oleh Portsentry

- Pengujian ping of death pada Snort : Pengujian serangan berupa ping of death dilakukan untuk menguji apakah Snort mampu mendeteksi jenis serangan tersebut atau tidak. Setelah dilakukan pengujian serangan Snort, hasilnya Snort dapat mendeteksi adanya serangan tersebut seperti yang nampak pada gambar 12 .

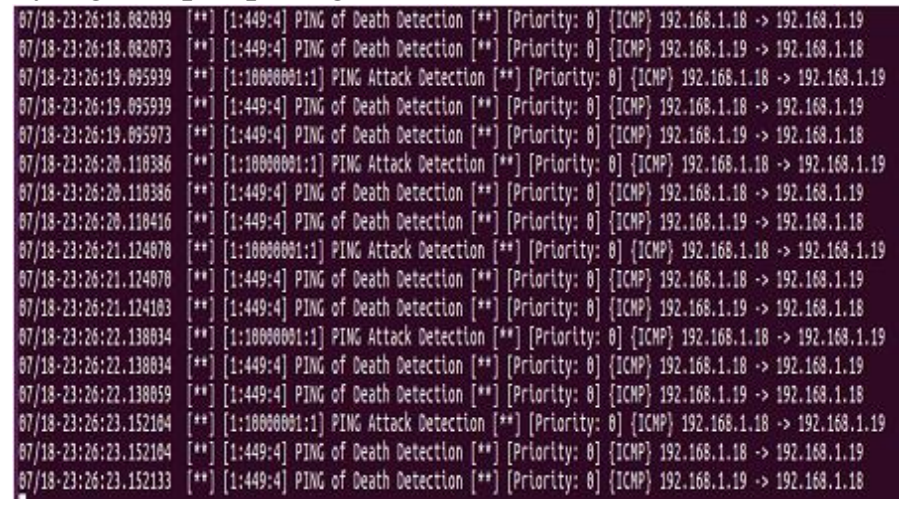

Gambar 12. Hasil Terdeteksinya Serangan Ping of Death Oleh Snort

Pengujian scanning port dilakukan sebanyak dua kali pengujian dengan menggunakan program aplikasi scanner yang berbeda yaitu program aplikasi Zenmap dan Advanced Port Scanner.

- Pengujian scanning port pada Portsentry : Pengujian serangan scanning port dilakukan untuk menguji apakah Portsentry dapat mendeteksi jenis serangan tersebut atau tidak. Namun setelah diterapkannya Portsentry hasilnya pengujian scanning port yang dilakukan 
menggunakan program aplikasi Zenmap menunjukkan hasil dari Portsentry yang dapat mendeteksi serangan sehingga dapat mencatat dan mengingat alamat IP dari attacker yaitu 192.168.1.18.

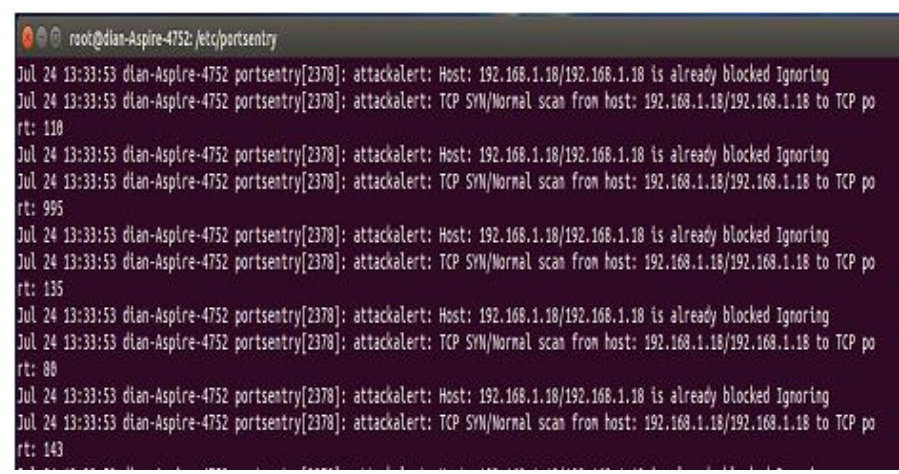

Gambar 13. Hasil Terdeteksinya Serangan scanning port Oleh Portsentry

Selain itu adalah IP attacker juga diblokir, ketika melakukan ping konkesi menggunakan program aplikasi command prompt hasil reject connection oleh Portsentry sehingga tidak dapat terhubung kembali pada server, sesuai dengan metode yang digunakan yaitu IPS. Hasil dari pengujian tersebut seperti yang ditunjukkan pada gambar 14 .

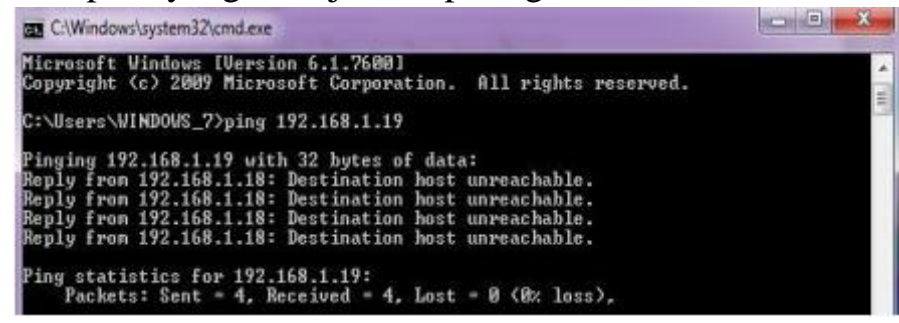

Gambar 14. Hasil IP Atttacker yang telah berhasil diblokir oleh Portsentry

- Pengujian scanning port pada Snort : Pengujian serangan scanning port dilakukan untuk menguji apakah Snort dapat mendeteksi jenis serangan tersebut atau tidak. Setelah diterapkannya Snort hasilnya pengujian scanning port yang dilakukan menggunakan program aplikasi Zenmap menunjukkan hasil dari Snort yang dapat mendeteksi adanya serangan dan dapat memberikan peringatan atau notifikasi pada sistem server, sesuai dengan metode yang digunakan yaitu IDS. Hasil dari pengujian Snort yang dapat memberikan notifikasi seperti yang nampak pada gambar 15 .

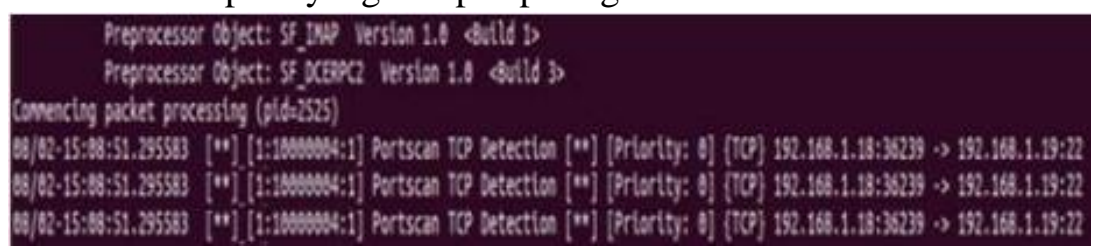

Gambar 15. Hasil Terdeteksinya Serangan Scanning Port oleh Snort

Pengujian sniffing dilakukan untuk menguji keberhasilan Portsentry dan Snort dengan menggunakan program aplikasi Wireshark.

- Pengujian sniffing pada Portsentry : Pengujian serangan sniffing dilakukan untuk menguji apakah Portsentry dapat mendeteksi jenis serangan tersebut atau tidak. Namun setelah diterapkannya Portsentry hasilnya pengujian sniffing yang dilakukan menggunakan program aplikasi Wireshark menunjukkan hasil dari Portsentry yang tidak dapat mendeteksi serangan sniffing. 


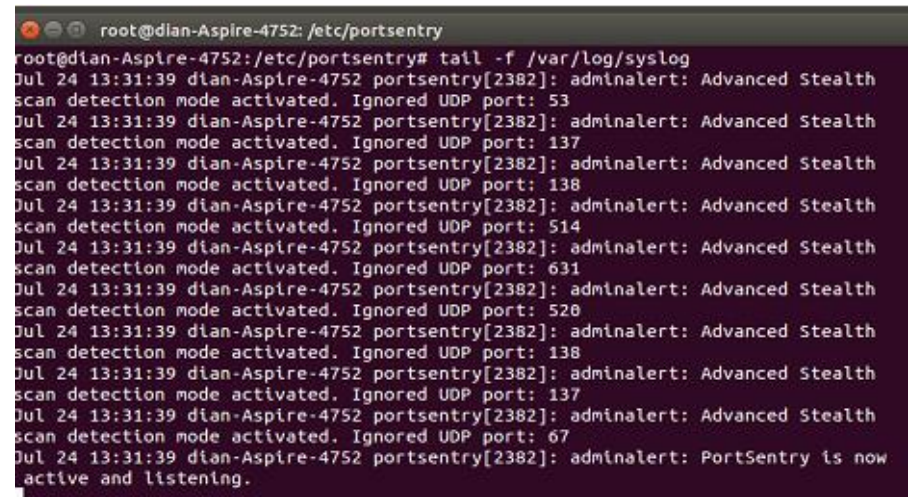

Gambar 16. Hasil Tidak Tedeteksinya Serangan Sniffing oleh Portsentry

Hal ini dibuktikan dengan Wireshark yang masih bisa melakukan capture berupa alamat IP server yaitu 192.168.1.19 beserta informasinya seperti yang nampak pada gambar 17.

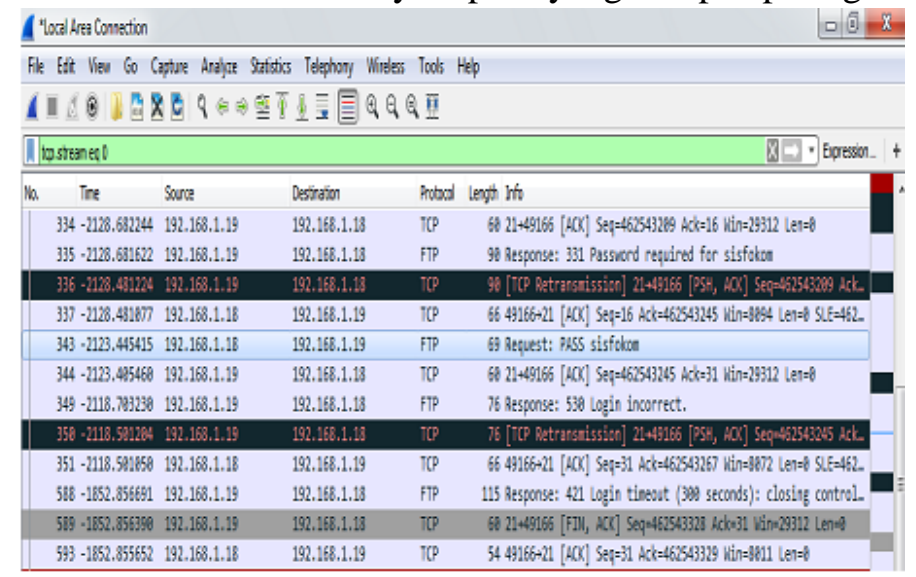

Gambar 17. Hasil Serangan Sniffing Oleh Wireshark

Login menggunakan username shahkhadafi dan password masih dapat dilakukan dengan mengakses IP FTP Server seperti pada gambar 18.

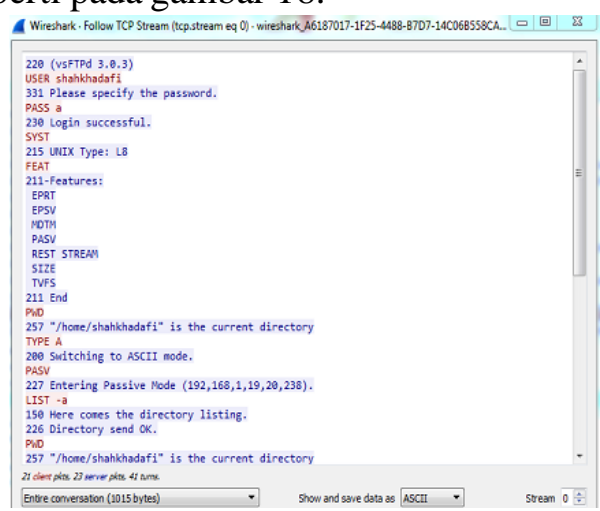

Gambar 18. Hasil Serangan Sniffing Oleh Wireshark

- Pengujian sniffing pada Snort : Pengujian serangan sninffing dilakukan untuk menguji apakah Snort dapat mendeteksi jenis serangan tersebut atau tidak. Berikut ini adalah konfigurasi Snort mode sniffer seperti yang nampak pada gambar 16, perintah -vde pada Snort memiliki arti masing-masing yaitu perintah $-\mathrm{v}$ untuk melihat header TCP/IP paket yang lewat, perintah $-\mathrm{d}$ untuk melihat isi paket dan perintah - e untuk melihat header link layer paket seperti ethernet header. Sedangkan perintah port 21 menunjukkan port FTP.

(x) root@dian-Aspire-4752:/etc/snort

rootedian-Aspire-4752:/etc/snort\# snort -vde -i etho:etho:1 tep port 21

Gambar 19. Perintah Snort mode sniffer 
Setelah diterapkannya Snort mode sniffer hasilnya pengujian sniffing yang dilakukan menggunakan program aplikasi Wireshark menunjukkan hasil dari Snort dapat mendeteksi adanya serangan tanpa melakukan pemblokiran terhadap serangan, hal ini dikarenakan Snort dapat dikonfigurasi mode sniffer, dan dengan mode tersebut dapat membaca paket IP dari penyusup atau attacker yang mencoba melakukan sniffing pada FTP server.

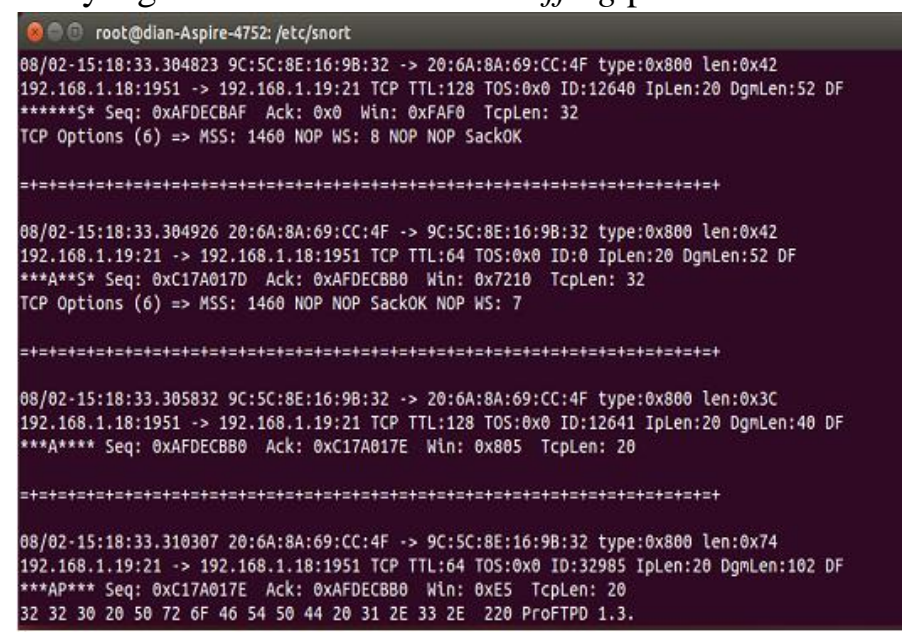

Gambar 20. Hasil Tedeteksinya Serangan Sniffing oleh Snort

Pembahasan yang akan disajikan ini meliputi hasil dari pengujian serangan sebelumnya yaitu ping-of-death, port scanning, dan sniffing. Hasil pengujian sistem kemananan FTP server menggunakan IDS dan IPS dengan Portsentry dan Snort menunjukkan bahwa sistem keamanan ini berjalan dengan baik. Terbukti dari yang mana komputer attacker ketika melakukan beberapa pengujian dapat terdeteksi dan juga dapat terblokir baik melalui IP address yang digunakan maupun juga pembacaan traffic jaringan yang dilakukan monitoring. Hasil dari pengujian tersebut dijasikan pada tabel 1 di bawah ini.

Tabel 1. Hasil Pengujian Sistem IDS dan IPS pada FTP Server

\begin{tabular}{cccc}
\hline \multirow{2}{*}{ Type of attack } & \multicolumn{3}{c}{ Computer with FTP service } \\
\cline { 2 - 4 } & Application for IDS / IPS & States IDS & States IPS \\
\hline \multirow{2}{*}{ Ping-of-Death } & Portsentry & Undetected & Unblock \\
& Snort & Detected & Unblock \\
\hline \multirow{2}{*}{ Scanning port } & Portsentry & Detected & Blocked \\
& Snort & Detected & Unblock \\
\hline \multirow{2}{*}{ Sninffing } & Portsentry & Undetected & Unblock \\
& Snort & Detected & Unblock \\
\hline
\end{tabular}

\section{KESIMPULAN}

Kesimpulan yang dapat diambil setelah melakukan penelitian mengenai sistem kemananan FTP server menggunakan IDS dan IPS dengan Portsentry dan Snort antara lain yaitu :

1. Aplikasi Portsentry sangat efektif dan sangat baik dalam mendeteksi adanya aktivitas scanning port melalui syntax command BLOCK_TCP dan BLOCK_UDP.

2. Aplikasi Portsentry sangat baik dalam memblokir serangan dari attacker, hal ini dikarenakan Portstentry memiliki mekanisme untuk mencatat IP address yang dimilki oleh attacker melalui file system portsentry.ignore.static. Sehingga apabila attacker ingin melakukan koneksi kembali pada komputer FTP server maka hasilnya tidak dapat terkoneksi, dalam hal ini Portsentry melakukan pemblokiran IP address.

3. Aplikasi Snort sangat efektif ketika mendeteksi semua jenis serangan baik itu serangan ping of death, scanning port maupun sniffing, hal ini dikarenakan Snort memiliki mekanime yaitu Snort mode detection untuk memberikan informasi peringatan atau alert kepada admin 
jaringan bila terdapat attacker atau intruder melalui rules command di dalam file system Snort.

4. Penggunaan aplikasi Portsentry dan Snort yang cukup efektif dalam mendeteksi dan memproteksi serangan dikarenakan keduanya mampu melengkapi kekurangan dari masingmasing kinerjanya.

5. Implementasi teknik Intrusion Detection System (IDS) dan Intrusion Prevention System IPS sangat mudah dan sederhana untuk diimplementasikan untuk keamanan komputer server.

\section{Daftar Pustaka}

[1] B. Prabadevi and N. Jeyanthi, "A Review on Various Sniffing Attacks and its Mitigation Techniques," Indones. J. Electr. Eng. Comput. Sci., vol. 12, no. 3, pp. 1117-1125, Dec. 2018, doi: 10.11591/ijeecs.v12.i3.pp1117-1125.

[2] S. Khadafi, S. Nurmuslimah, and F. K. Anggakusuma, "Implementasi Firewall dan Port Knocking Sebagai Keamanan Data Transfer Pada FTP Server Berbasiskan Linux Ubuntu Server,"

J. Ilm. NERO, vol. 4, no. 3, pp. 181-188, Nov. 2019, doi: http://dx.doi.org/10.21107/nero.v4i3.137.

[3] S. Khadafi, B. D. Meilani, and S. Arifin, "Sistem Keamanan Open Cloud Computing Menggunakan Menggunakan IDS (Intrusion Detection System) Dan IPS (Intrusion Prevention System), $\quad J$. IPTEK, vol. 21, no. 2, pp. 67-76, 2017, doi: https://doi.org/10.31284/j.iptek.2017.v21i2.207.

[4] N. A. Alrajeh, S. Khan, and B. Shams, "Intrusion Detection Systems in Wireless Sensor Networks: A Review," Int. J. Distrib. Sens. Netw., vol. 9, no. 5, p. 167575, May 2013, doi: $10.1155 / 2013 / 167575$.

[5] B. Himawan and T. Hidayat, "Perancangan Host-Based Intrusion Detection System Berbasis Artificial Neural Network," Semin. Nas. Apl. Teknol. Inf. 2007 SNATI 2007, p. B-69-B73, 2007.

[6] N. Khamphakdee, N. Benjamas, and S. Saiyod, "Improving Intrusion Detection System Based on Snort Rules for Network Probe Attacks Detection with Association Rules Technique of Data Mining," J. ICT Res. Appl., vol. 8, no. 3, pp. 234-250, Mar. 2015, doi: http://dx.doi.org/10.5614\%2Fitbj.ict.res.appl.2015.8.3.4.

[7] S. Agustini and A. Mudzakir, "Rancang Bangun Jaringan Komputer Dengan Bandwidth Management Menggunakan Teknik Brust Limit Dan Firewall Sebagai Pengaman Jaringan,” J. Ilm. NERO, vol. 4, no. 3, pp. 189-195, Nov. 2019, doi: http://dx.doi.org/10.21107/nero.v4i3.

[8] S. A. Prihasmoro, Y. Rachmawati, and E. Fatkhiyah, "Simulasi Sistem Deteksi Penyusup Dalam Jaringan Komputer Berbasis Web Interface Serta Pencegahan Untuk Meningkatkan Keamanan," J. JARKOM, vol. 4, no. 1, pp. 50-59, Jul. 2016.

[9] M. Anif, S. Hws, and M. D. Huri, "Penerapan Intrusion Detection System (IDS) dengan metode Deteksi Port Scanning pada Jaringan Komputer di Politeknik Negeri Semarang," J. TELE, vol. 13, no. 1, pp. 25-30, Mar. 2015.

[10] A. Abdollahi and M. Fathi, "An Intrusion Detection System on Ping of Death Attacks in IoT Networks," Wirel. Pers. Commun., vol. 112, no. 4, pp. 2057-2070, Jun. 2020, doi: 10.1007/s11277-020-07139-y.

[11] M. Bhavsar, D. P. Sharma, and M. Gokani, "Port scanning using Nmap," Int. J. Eng. Dev. Res., vol. 5, no. 4, pp. 1536-1537, Dec. 2017.

[12] A. Kulshrestha and S. K. Dubey, "A Literature Review on Sniffing Attacks in Computer Network," Int. J. Adv. Eng. Res. Sci., vol. 1, no. 2, pp. 67-73, Jul. 2014. 